\title{
Retos del uso de las tecnologías de información y comunicación en el proceso de las contrataciones públicas electrónicas: sector petrolero de Mexico*
}

\section{Gisela María Pérez Fuentes"* Karla Cantoral Domínguez ${ }^{* *}$}

\begin{abstract}
RESUMEN
En México, la reforma en materia energética introdujo una serie de cambios en el sector petrolero, entre los que se encuentra la conformación de PEMEX como empresa productiva del Estado. En este artículo se analizan los cambios de PEMEX y el impacto del gobierno abierto en las contrataciones públicas electrónicas en materia de adquisiciones, arrendamientos y servicios, como parte de la estrategia para favorecer la libre competencia en la que las licitaciones cumplan con los principios de transparencia, máxima publicidad, igualdad, competitividad y sencillez. El proceso de contrataciones públicas se puede realizar de forma física o electrónica o ambas, sin embargo, como estrategia para combatir la corrupción y favorecer la rendición de cuentas, el reto es que todo el proceso de contratación pública se realice a través del uso de las tecnologías de información y comunicación mediante la plataforma electrónica diseñada por PEMEX, que garantice autenticidad y confidencialidad de la información a las personas fisicas o juridicas que deseen participar en dicho proceso.
\end{abstract}

\section{PALABRAS CLAVE}

Contrataciones públicas electrónicas, gobierno abierto, tecnologías de información y comunicación, sector petrolero.

\begin{abstract}
In Mexico, the energy reform introduced a series of changes in the petroleum sector, among the development of PEMEX as a productive state enterprise. This article analyzes the changes in PEMEX and the impact of open government on electronic allocation of public contracts in terms of acquisitions, leases and services, as part of the free competition strategy in which tenders comply with the principles of transparency, maximum publicity, equality, competitiveness and simplicity. The allocation process can be carried out either physically or electronically or both, however, as a strategy to combat corruption and promote accountability, the challenge is for the entire public allocation process to be carried out through the use of information and communication technologies through the electronic platform designed by PEMEX, which guarantees authenticity and confidentiality of information to natural or legal persons wishing to participate in said process.
\end{abstract}

\section{KEYWORDS}

Public allocation of contracts, open government, information and communication technologies, petroleum sector.

*Artículo recibido el 16 de agosto de 2017 y aceptado el 24 de septiembre de 2017

**Universidad Juárez Autónoma de Tabasco. (giselapef@hotmail.com) orcid 0000-0001-7616-9193

***Universidad Juárez Autónoma de Tabasco. (karlacantoral@gmail.com) orcid 0000-0001-9778-4021 
SUMARIO

1. Introducción

2. De órgano de la administración pública a empresa productiva del Estado

3. Objeto de Pemex como empresa productiva

4. Órganos directivos y de organización en Pemex

5. Interpretación judicial en México sobre la reforma energética de 2013

6. Gobernanza de las contrataciones públicas electrónicas en México en el sector petrolero

7. E-gobierno o gobierno electrónico

8. Datos abiertos

9. Política sobre datos abiertos en México

10. Contrataciones públicas electrónicas en el sector petrolero

11. Conclusiones

\section{Introducción}

La reforma constitucional en materia energética ocurrida en México en el año $2013^{1}$ ha generado una serie de desafíos que van desde los cambios en la estructura jurídica y organizacional de Petróleos Mexicanos (Pemex), las modalidades de contratación para la realización del proceso de exploración y extracción del petróleo y demás hidrocarburos, y todas aquellas actividades dirigidas a su transformación y comercialización.

El objetivo del presente artículo es analizar los cambios de Pemex como empresa productiva del Estado y el impacto de la gobernanza de las contrataciones públicas electrónicas en materia de adquisiciones, arrendamientos y servicios en la transformación de su naturaleza jurídica. Dicha transformación es parte de la estrategia para favorecer la libre competencia, y que las licitaciones cumplan con los principios de transparencia, máxima publicidad, igualdad, competitividad y sencillez.

110 Así también se establecen las diferencias entre gobierno electrónico y datos abiertos y se explica el proceso de la política de datos abiertos en México para hacer más eficientes los servicios y lograr una participación proactiva de la sociedad.

\footnotetext{
1 "Decreto por el que se reforman y adicionan los artículos 25, 27 y 28 de la Constitución Política de los Estados Unidos Mexicanos en Materia de Energía", Diario Oficial de la Federación, 20 de diciembre, 2013.
} 
Nuestra hipótesis es que las tecnologías de información y comunicación en las contrataciones públicas en el sector petrolero son un instrumento que favorece el gobierno abierto en México. Por lo anterior, a partir de la nueva estructura de Pemex como empresa productiva del Estado, se presenta el sistema electrónico que se utiliza en el proceso de las contrataciones públicas y la forma de relacionarse con aquellas personas físicas o empresas que deseen participar como proveedores.

\section{De órgano de la administración pública a empresa productiva del Estado}

Antes de la reforma de 2013, Pemex era una entidad paraestatal. Su fundamento constitucional se encontraba en el artículo 90. Mediante él se reconoce que la administración pública federal será centralizada y paraestatal. ${ }^{2}$

En México, la administración pública centralizada la integran la Oficina de la Presidencia de la República, las Secretarías de Estado, la Consejería Jurídica del Ejecutivo Federal y los Órganos Reguladores Coordinados. A su vez, podrán contar con órganos administrativos desconcentrados que les estarán jerárquicamente subordinados y tendrán facultades específicas para resolver sobre la materia y dentro del ámbito territorial que se determine en cada caso. ${ }^{3}$

Por otra parte, la administración pública paraestatal la componen los organismos descentralizados, las empresas de participación estatal, las instituciones nacionales de crédito, las organizaciones auxiliares nacionales de crédito, las instituciones nacionales de seguros y de fianzas y los fideicomisos. ${ }^{4}$

En la abrogada Ley de Petróleos Mexicanos de 2008, se consideraba que Pemex era un organismo descentralizado con fines productivos, personalidad jurídica y patrimonio propios. Su objetivo consistía en llevar a cabo la exploración, explotación y demás actividades en el área estratégica del petróleo, hidrocarburos y la petroquímica básica. Asimismo, ejercía la conducción central y dirección estratégica de la industria petrolera. Por tanto, formaba parte de la administración pública federal.

\footnotetext{
${ }^{2}$ El primer párrafo del artículo 90 de la Constitución Federal establece: "Artículo 90. La Administración Pública Federal será centralizada y paraestatal conforme a la Ley Orgánica que expida el Congreso, que distribuirá los negocios del orden administrativo de la Federación que estarán a cargo de las Secretarias de Estado y definirá las bases generales de creación de las entidades paraestatales y la intervención del Ejecutivo Federal en su operación". ${ }^{3} \mathrm{Al}$ respecto, véase los artículos 3 y 17 de la Ley Orgánica de la Administración Pública Federal publicada en el Diario Oficial de la Federación, 29 de diciembre, 1976; última reforma, 19 de mayo, 2017.

${ }^{4}$ Cfr. Artículo 3 de la Ley Orgánica de la Administración Pública Federal.
} 
En la reforma constitucional de 2013, se incorporó de forma expresa el modelo de las empresas productivas del Estado. Así lo podemos observar en los artículos 25 párrafo quinto y 27 párrafo séptimo de la Constitución. ${ }^{5} \mathrm{~A}$ partir del año 2014, Pemex se transformó en una empresa productiva del Estado; conservó su personalidad jurídica, así como la titularidad de todos los bienes, derechos y obligaciones que le corresponden, excepto los que fija la Ley de Hidrocarburos. ${ }^{6}$ Esto quiere decir que el propietario de la empresa productiva Pemex es el Gobierno Federal, y su régimen jurídico se encuentra determinado en la ley especial.

Como refiere Guajardo Soto, ${ }^{7}$ debemos tener presente que la empresa pública moderna surge durante la Revolución Industrial, por la necesidad de la autoridad pública de regular, coordinar y definir derechos de las infraestructuras en las áreas urbanas, para la producción de bienes en masa y la construcción de redes. En la década de los setenta, se adoptaron en los países de América Latina los siguientes modelos: a) Empresa autónoma creada por ley, con personalidad jurídica y patrimonio e ingresos propios que realiza actividades de la administración pública; $b$ ) Sociedad de economía mixta, empresa dotada de personalidad jurídica de derecho privado, creada por ley para la explotación de actividades

\footnotetext{
${ }^{5}$ Artículo 25, párrafo quinto: "El sector público tendrá a su cargo, de manera exclusiva, las áreas estratégicas que se señalan en el artículo 28, párrafo cuarto de la Constitución, manteniendo siempre el Gobierno Federal la propiedad y el control sobre los organismos y empresas productivas del Estado que en su caso se establezcan. Tratándose de la planeación y el control del sistema eléctrico nacional, y del servicio público de transmisión y distribución de energía eléctrica, asi como de la exploración y extracción de petróleo y demás hidrocarburos, la Nación llevará a cabo dichas actividades en términos de lo dispuesto por los párrafos sexto y séptimo del artículo 27 de esta Constitución. En las actividades citadas la ley establecerá las normas relativas a la administración, organización, funcionamiento, procedimientos de contratación y demás actos jurídicos que celebren las empresas productivas del Estado, así como el régimen de remuneraciones de su personal, para garantizar su eficacia, eficiencia, honestidad, productividad, transparencia y rendición de cuentas, con base en las mejores prácticas, y determinará las demás actividades que podrán realizar". Así también el artículo 27, párrafo séptimo establece: "Tratándose del petróleo y de los hidrocarburos sólidos, líquidos o gaseosos, en el subsuelo, la propiedad de la Nación es inalienable e imprescriptible y no se otorgarán concesiones. Con el propósito de obtener ingresos para el Estado que contribuyan al desarrollo de largo plazo de la Nación, ésta llevará a cabo las actividades de exploración y extracción del petróleo y demás hidrocarburos mediante asignaciones a empresas productivas del Estado o a través de contratos con éstas o con particulares, en los términos de la Ley Reglamentaria. Para cumplir con el objeto de dichas asignaciones o contratos las empresas productivas del Estado podrán contratar con particulares. En cualquier caso, los hidrocarburos en el subsuelo son propiedad de la Nación y así deberá afirmarse en las asignaciones o contratos.

${ }^{6}$ Cfr. Artículo tercero transitorio de la Ley de Petróleos Mexicanos, Diario Oficial de la Federación, 11 de agosto, 2014. En adelante, LPM.

7 Guajardo Soto, Guillermo, "La empresa pública y sus definiciones en el largo plazo" en Guillermo Guajardo y Alejandro Labrador (coords.), La empresa pública en México y en América Latina: entre el mercado y el Estado, México, Universidad Nacional Autónoma de México - Centro de Investigaciones Interdisciplinarias en Ciencias y Humanidades - Instituto Nacional de Administración Pública, 2015, pp. 23-35.
} 
económicas bajo la forma de una sociedad anónima cuyas acciones pertenecen, en proporción mayoritaria, al Estado o a entidad de administración indirecta $;^{8} \mathrm{y}$ c) Empresa pública, aquella entidad dotada de personalidad jurídica de derecho privado, con patrimonio propio y capital exclusivamente del Estado, creada en virtud de una ley para explotar una actividad económica que el Gobierno ha debido ejercitar por contingencias o conveniencia administrativa.

\section{Objeto de Pemex como empresa productiva}

Como podemos observar, la nueva ley de Petróleos Mexicanos tiene por objeto regular la organización, administración, funcionamiento, operación, control, evaluación y rendición de cuentas de la empresa productiva del Estado Pemex. También establece su régimen especial en materia de: a) Empresas productivas subsidiarias y empresas filiales; $b$ ) Remuneraciones; c) Adquisiciones, arrendamientos, servicios y obras; $d$ ) Bienes; e) Responsabilidades; f) Dividendo estatal; $g$ ) Presupuesto, y $h$ ) Deuda. ${ }^{9}$

La ley de Petróleos Mexicanos consta de 118 artículos. Se divide en dos títulos: "De Petróleos Mexicanos como empresa productiva del Estado" y "Del gobierno corporativo". Lo anterior es consecuencia de la aplicación de los principios sobre gobierno corporativo de la oCDE y sus recomendaciones en cuanto al diseño que deben seguir las empresas públicas en la actualidad, así como las buenas prácticas internacionales. ${ }^{10}$

Este cambio a empresa pública implica que Pemex debe regirse conforme a las reglas de su ley especial. Así también, de forma supletoria, se dejan las reglas del derecho civil y mercantil. El legislador estableció además que en caso de duda se deberá favorecer la interpretación que privilegie la mejor realización de los fines y objeto de Pemex conforme a su naturaleza jurídica

\footnotetext{
${ }^{8}$ El artículo 25 párrafo cuarto de la Constitución Federal establece: "Al desarrollo económico nacional concurrirán, con responsabilidad social, el sector público, el sector social y el sector privado, sin menoscabo de otras formas de actividad económica que contribuyan al desarrollo de la Nación". Este párrafo nos da las bases para el sistema de economía mixta en México, entre las cuales se consideran las empresas públicas, pero no las de tipo neoliberal.

${ }^{9} \mathrm{Cfr}$. artículo 1 de la LPM.

${ }^{10}$ Los principios de gobierno corporativo de la OCDE SOn: a) Garantizar la base de un marco eficaz para el gobierno corporativo; b) Los derechos de los accionistas y funciones clave en el ámbito de la propiedad; c) Tratamiento equitativo de los accionistas; d) El papel de las partes interesadas en el gobierno corporativo; e) Revelación de datos y transparencia, y f) Las responsabilidades del Consejo. véase Organización para la Cooperación y el Desarrollo Económico, Principios de gobierno corporativo de la ocde, París, ocde, 2004, pp. 1-68; Organización Para la Cooperación y el Desarrollo Económico, Directrices sobre el Gobierno Corporativo de las Empresas Públicas, Paris, oCDE, 2011, pp. 1-64.
} 
de empresa productiva del Estado con régimen especial, de forma que pueda competir con eficacia en la industria energética. ${ }^{11}$

Pemex tiene por objeto llevar a cabo, en términos de la legislación aplicable, la exploración y extracción del petróleo y de los carburos de hidrógeno sólidos, líquidos o gaseosos, así como su recolección, venta y comercialización. Asimismo, podrá llevar a cabo entre otras actividades las siguientes: ${ }^{12}$

- Refinación, transformación, transporte, almacenamiento, distribución, venta, exportación e importación de petróleo e hidrocarburos y los productos que se obtengan de su refinación o procesamiento y sus residuos, y la prestación de servicios relacionados con dichas actividades.

- Procesamiento de gas y las actividades industriales y comerciales de la petroquímica; desarrollo y ejecución de proyectos de ingeniería, investigación, actividades geológicas, geofísicas, supervisión, prestación de servicios a terceros y todas aquellas relacionadas con la exploración, extracción y demás actividades que forman parte de su objeto, a precios de mercado.

Pemex podrá realizar todas aquellas actividades que sean necesarias para el cabal cumplimiento de su objeto tanto en México, su zona económica exclusiva, como en el extranjero. El panorama en el ámbito internacional nos permite afirmar que las empresas públicas permiten al Estado alcanzar una situación financiera saludable, ${ }^{13}$ siempre y cuando sus acciones sean transparentes y contemplen mecanismos de rendición de cuentas para evitar casos de corrupción en los procesos de asignación.

Como ejemplo en cuanto a la rentabilidad de las empresas públicas en el mundo, se citan ICBC y China Construction Bank de China; en materia energética, a pesar de la desaceleración en los precios del petróleo ocurrida durante el último año, encontramos las empresas Marathon Petroleum de Estados Unidos, China Petroleum \& Chemical de China y Gazprom de Rusia. ${ }^{14}$

Otro elemento que conviene tomar en cuenta sobre la naturaleza jurídica de la empresa productiva del Estado es su facultad para realizar asociaciones,

\footnotetext{
${ }^{11} \mathrm{Cfr}$. Artículo 3 de la LPM.

${ }^{12}$ Cfr. Artículo 5 de la LPM.

${ }^{13}$ FLORIO, MASSIMO, "Empresas públicas contemporáneas en una perspectiva global: teoria y evidencia", Revista del CLAD Reforma y Democracia, núm. 60, pp. 59-102.

${ }^{14}$ Al respecto, véase "The World's Biggest Public Companies", Forbes. [Consulta: 2 de junio, 2017]. Disponible en: https://www.forbes.com/global2000/list/\#
} 
tales como actividades, operaciones o servicios para el cumplimiento de su objeto. Lo anterior con apoyo de sus empresas productivas subsidiarias y empresas filiales, o mediante la celebración de contratos, convenios, alianzas o asociaciones o cualquier acto jurídico, con personas físicas o morales de los sectores público, privado o social, nacional o internacional. ${ }^{15}$

Pemex puede celebrar actos jurídicos y contratos con el Gobierno Federal y con personas físicas o morales para cumplir con su objeto. Sin embargo, el Estado mexicano mantendrá en exclusiva la propiedad sobre los hidrocarburos que se encuentren en el subsuelo. ${ }^{16}$ Esto le otorga facultades de goce y disfrute de estos recursos naturales con las limitaciones que se encuentren fijadas por las leyes $;{ }^{17}$ es el caso de la apertura de mercado a la exploración y extracción del petróleo.

\section{4. Órganos directivos y de organización en Pemex}

Conforme con los principios establecidos en la ley de la materia, Pemex es dirigido y administrado por un consejo de administración y un director general. El consejo de administración es el órgano supremo de administración; es el responsable de definir las políticas, lineamientos y visión estratégica de Pemex, sus empresas productivas subsidiarias y sus empresas filiales. ${ }^{18}$ El director general debe llevar a cabo la gestión, operación, funcionamiento y ejecución de los objetivos de Pemex, sujetándose a las estrategias, políticas y lineamientos aprobados por el consejo de administración. ${ }^{19}$ Sin embargo, en atención a las últimas recomendaciones emitidas por la OCDE, la empresa productiva del Estado podría garantizar un marco de integridad exhaustivo y eficaz para los integrantes de su consejo de administración y promover una cultura de integridad entre sus empleados. ${ }^{20}$

Pemex podrá contar con empresas productivas subsidiarias y empresas filiales. Actuará a través de empresas productivas subsidiarias para realizar actividades de exploración y extracción de hidrocarburos. Las demás actividades de Pemex podrá realizarlas directamente, a través de empresas filiales,

\footnotetext{
${ }^{15}$ Cfr. Artículo 6 de la LPM.

${ }^{16}$ Cfr. Artículo 8 de la LPM.

${ }^{17}$ Véase Pérez Fuentes, Gisela Maria y Cantoral Dominguez, Karla, Teoría y próctica de los derechos reales en estudios de caso, México, Novum, 2014, pp. 99-112.

${ }^{18} \mathrm{Cfr}$. Artículos 12 y 13 de la LPM.

${ }^{19} \mathrm{Cfr}$. Artículo 46 de la LPM.

${ }^{20}$ Organización para la Cooperación y el Desarrollo Económico, Estudio sobre las contrataciones públicas de Pemex. Adaptándose al cambio en la industria petrolera, Paris, OCDE, 2017, pp. 15-17.
} 
empresas en las que participe de manera minoritaria, directa o indirectamente, o mediante cualquier figura de asociación o alianza que no sea contraria a la ley. ${ }^{21}$

Las empresas productivas subsidiarias son empresas productivas del Estado, con personalidad jurídica y patrimonio propio. Se organizarán y funcionarán conforme a lo dispuesto en la ley de la materia y se sujetarán a la dirección de Pemex. Las empresas productivas subsidiarias tendrán por objeto las actividades que determine el consejo de administración de Pemex. Operarán conforme con su régimen especial en materia de presupuesto, deuda, adquisiciones, arrendamientos, servicios y obras; responsabilidades administrativas; remuneraciones; bienes y dividendo estatal. ${ }^{22}$ Como podemos observar, las contrataciones públicas se rigen a partir de la ley especial, su reglamento y demás instrumentos normativos que se expidan para tales efectos. Esto siempre y cuando no se dejen de observar los principios que establece la Constitución Federal. ${ }^{23}$

Además, el consejo de administración tiene la facultad de emitir las disposiciones para los procedimientos antes mencionados. Entre éstas, destaca publicar la información sobre contrataciones que realicen las empresas en su página electrónica, conforme con lo previsto en la Ley Federal de Transparencia y Acceso a la Información Pública Gubernamental, así como prever las facilidades necesarias para que los procedimientos se realicen, preferentemente por medios electrónicos. ${ }^{24}$

La ley especial dispone que las propuestas en materia de adquisiciones, arrendamientos y servicios podrán presentarse y analizarse a través de medios electrónicos, en los términos que establezca el consejo de administración, observando que las licitaciones cumplan con los principios de transparencia, máxima publicidad, igualdad, competitividad y sencillez. ${ }^{25}$

Son empresas filiales de Pemex aquellas en las que participe, directa o indirectamente, en más de cincuenta por ciento de su capital social, con independencia de que se constituyan conforme a la legislación mexicana o a la

\footnotetext{
${ }^{21}$ Cfr. Artículo 59 de la LPM.

${ }^{22}$ Cfr. Artículo 60 de la LPM.

${ }^{23}$ Al respecto, el artículo 134 de la Constitución Federal establece en su tercer párrafo: "Las adquisiciones, arrendamientos y enajenaciones de todo tipo de bienes, prestación de servicios de cualquier naturaleza y la contratación de obra que realicen, se adjudicarán o llevarán a cabo a través de licitaciones públicas mediante convocatoria pública para que libremente se presenten proposiciones solventes en sobre cerrado, que será abierto públicamente, a fin de asegurar al Estado las mejores condiciones disponibles en cuanto a precio, calidad, financiamiento, oportunidad y demás circunstancias pertinentes".

${ }^{24}$ Cfr. Artículo 76 fracciones IV y XI de la LPM.

${ }^{25}$ Cfr. Artículo 77 de la LPM.
} 
extranjera. Las empresas filiales no serán entidades paraestatales y tendrán la naturaleza jurídica y se organizarán conforme al derecho privado del lugar de su constitución o creación. ${ }^{26}$

Es interesante destacar que en cuanto a las actividades de exploración y extracción de hidrocarburos que se realicen en México a través de asignaciones y contratos, se deberá alcanzar, en promedio, al menos treinta y cinco por ciento de contenido nacional. ${ }^{27}$ Además, la Secretaría de Economía será quien establezca la metodología para medir el contenido nacional en asignaciones y contratos para la exploración y extracción y en la industria de hidrocarburos. Asimismo, debe verificar su cumplimiento en términos de las disposiciones que para tal efecto expida. ${ }^{28}$ Para ello, debe usar conceptos fundamentales de esta actividad, tales como bienes y servicios contratados, considerando su origen, la mano de obra nacional y de trabajo calificada, la capacitación de la mano de obra nacional, la inversión en infraestructura física local y regional, y la transferencia de la tecnología. ${ }^{29}$

Esta metodología en cuanto al contenido nacional que debe considerarse en las actividades vinculadas con el sector energético podría considerarse como una estrategia de seguimiento a las recomendaciones de la oCDE en cuanto se refiere a empresas multinacionales para garantizar una conducta empresarial responsable. ${ }^{30}$

\section{Interpretación judicial en México sobre la reforma energética de 2013}

En enero de 2017, la Segunda Sala de la Suprema Corte de Justicia de la Nación emitió una resolución en la cual se pronunció con respecto a los alcances de la reforma energética. ${ }^{31}$ Considera que el nuevo régimen constitucional y legal en materia de petróleo sólo contempla como área estratégica la exploración y

\footnotetext{
${ }^{26}$ Cfr. Artículo 61 de la LPM.

${ }^{27}$ La excepción a esta regla será en cuanto a exploración y extracción de hidrocarburos en aguas profundas y ultra profundas.

${ }^{28}$ Véase el artículo 46 de la "Ley de Hidrocarburos", Diario Oficial de la Federación, 11 de agosto, 2014; última reforma, 15 de noviembre, 2016.

${ }^{29}$ El 13 de noviembre de 2014 se publicó en el Diario Oficial de la Federación el acuerdo por el que la Secretaría de Economía establece la metodología para la medición del contenido nacional en asignaciones y contratos para la exploración y extracción de hidrocarburos, así como para los permisos en la industria de hidrocarburos.

30 Organización para la Cooperación y el Desarrollo Económico, Guía de la ocde de diligencia debida para la participación significativa de las partes interesadas del sector extractivo, Paría, oCDE, 2016, pp. 1-148; Organización PARA LA Cooperación y el DesarRollo EConómico, Línea directrices de la OCDE para empresas multinacionales, París, OCDE, 2011, pp. 1-99. ${ }^{31}$ Al respecto, véase el amparo en revisión 415/2015 resuelto el 25 de enero de 2017 por la Segunda Sala de la Suprema Corte de Justicia de la Nación, promovido por Petróleos Mexicanos y Pemex-Refinación.
} 
extracción. De ahí se entiende que el resto de las actividades que comprendía previo a la reforma del año 2013 ya no son área estratégica de la industria petrolera.

Además, como resultado de la reforma constitucional operó una apertura en el sector de los petrolíferos. Se estableció en las leyes especiales diversas medidas como de regulación asimétrica para limitar el poder dominante de Pemex, en tanto se logra una mayor participación de agentes económicos que propicien el desarrollo eficiente y competitivo de los mercados. ${ }^{32}$

En materia de energía, se está ante un nuevo modelo que reconoce la participación de terceros en lo que se llama la cadena de valor de los hidrocarburos, es decir, su participación en actos posteriores a la exploración y extracción de petróleo y de los demás hidrocarburos. Para ello, se cuenta hoy en día con la normatividad, cuyo objetivo es crear las condiciones adecuadas para un mercado abierto y competitivo en el mercado de combustibles, su comercialización y lo que ésta conlleva. ${ }^{33}$

En definitiva, el sistema jurídico en materia energética busca fomentar la libre competencia y concurrencia en los mercados de comercialización y expendio al público de los productos derivados de hidrocarburos. Como parte de este nuevo régimen, se analizará a continuación la forma en la que se ha realizado la transformación hacia las contrataciones públicas electrónicas en Pemex como estrategia de gobernanza.

\section{Gobernanza de las contrataciones públicas electrónicas en México en el sector petrolero}

El término gobernanza ${ }^{34}$ comenzó a utilizarse en Europa, especialmente en los medios académicos anglosajones, desde la década de 1990. Designa la eficacia, calidad y buena orientación en la intervención del Estado, que proporciona

\footnotetext{
32 "Tesis 2a. XLVI/2017", Décima Época, Gaceta del Semanario Judicial de la Federación, libro 40, tomo 2, marzo de 2017, p. 1392, bajo el rubro: Industria petrolera. La reforma constitucional en materia de energía publicada en el Diario Oficial de la Federación de 20 de diciembre de 2013, y los ordenamientos derivados, prevén medidas tendientes a propiciar el desarrollo eficiente y competitivo de los mercados.

33 "Tesis 2a. XLV/2017", Décima Época, Gaceta del Semanario Judicial de la Federación, libro 40, tomo 2, marzo de 2017, p. 1392, bajo el rubro: Industria petrolera. La reforma constitucional en materia de energía, publicada en el Diario Oficial de la Federación de 20 de diciembre de 2013, abrió la competencia en ese sector.

34 "Open government is not only about openness in informational terms but also about openness in interactive terms" [gobierno abierto no es únicamente la publicación de información sino la apertura que permite la interacción]. Cfr. MeIJeR, Albert, "Open government: connecting vision and voice", International Review of Administrative Sciences, núm. 78, pp. 10-29.
} 
a éste buena parte de su legitimidad. Esto a veces se define como una "nueva forma de gobernar" en la globalización del mundo posterior a la caída del Muro de Berlín en 1989. No obstante, sus orígenes pueden remontarse hasta la época de Platón, donde era sinónimo de dirigir o conducir. ${ }^{35}$

En la actualidad, el factor esencial de su renacimiento ha sido probablemente la necesidad de distinguir entre buen gobierno y gobierno. De manera que buen gobierno se refiere a las modalidades y maneras de gobernar, mientras que gobierno está relacionada con las instituciones, los agentes encargados de gobernar y al acto mismo de ejercer el gobierno. ${ }^{36}$

Entendemos el gobierno corporativo como una forma de gobernanza en las empresas públicas que no dependen únicamente del Estado en cuanto su patrimonio, pues la forma de propiedad se ejerce a través de un órgano de control, sin importar el porcentaje de participación. Pero otro punto crucial del gobierno corporativo es la apertura de la empresa pública en la sociedad de la información, a través del gobierno abierto.

La OCDE considera que el gobierno corporativo de las empresas públicas implica un reto trascendente en las economías de los Estados. En la actualidad existen diversas normativas asociadas a la idea de Gobierno Abierto en gran parte de los países miembros de la OCDE. En ellos se consideran leyes sobre acceso a la información y libertad de prensa; privacidad y datos personales; procedimientos administrativos y entidades fiscalizadoras; no obstante, la atención por parte de los países miembros ha sido limitada para garantizar la eficacia de estas leyes en su aplicación, especialmente en cuanto a los resultados alcanzados. Estos temas deben desarrollarse, de lo contrario sólo existe una carta de buenas intenciones que obstaculiza la transparencia y rendición de cuentas ante el uso de las tecnologías de información y comunicación. ${ }^{37}$

Gobierno abierto debe entenderse como una plataforma tecnológica institucional que convierta los datos gubernamentales en datos abiertos para permitir su uso, protección y colaboración por parte de los ciudadanos en los

\footnotetext{
${ }^{35}$ Alcántara, Armando, "Gobernanza, gobierno y gobernabilidad en la educación superior", en Bertha Lerner, Ricardo Uvalle y Roberto Moreno (coords.), Gobernabilidad y gobernanza en los albores del siglo xxI y reflexiones sobre el México contemporáneo, México, Universidad Nacional Autónoma de México, Instituto de Investigaciones Sociales, Instituto de Administración Pública del Estado de México, 2012, p. 164.

${ }^{36}$ SánChez, José JuAn, "Usos de los conceptos de gobernabilidad y gobernanza (una manera de diferenciarlos)" en Bertha Lerner, Ricardo Uvalle y Roberto Moreno (coords.), Gobernabilidad y gobernanza en los albores del siglo xxI y reflexiones sobre el México contemporáneo, México, Universidad Nacional Autónoma de México - Instituto de Investigaciones Sociales - Instituto de Administración Pública del Estado de México, 2012, pp. 217-265.

${ }^{37}$ Ramirez-Alujas, Álvaro, "Gobierno abierto y modernización de la gestión pública. Tendencias actuales y el (inevitable) camino que viene. Reflexiones seminales", Revista Enfoques: Ciencia Política y Administración Pública, vol. 9, núm. 15, pp. 99-125.
} 
procesos de decisión pública, rendición de cuentas y mejoramiento de los servicios públicos. ${ }^{38}$ No obstante, se requiere voluntad política para que sea una realidad en el sistema jurídico mexicano.

\section{E-gobierno o gobierno electrónico}

El E-Gobierno o gobierno electrónico, se refiere al empleo de internet y las Tecnologías de Información y Comunicación (TIC's) para conseguir una mejor administración del gobierno mediante la transparencia y el acceso público a la información, reforzando la asociación fundamental entre el sector público y los ciudadanos. Esta es una política que fomenta una participación más amplia de los ciudadanos en el proceso de gestión de los gobiernos. ${ }^{39}$

El gobierno abierto se articula a través de dos ejes fundamentales:

- La apertura de datos públicos (open data). Esto supone publicar información del sector público en formatos estándar, abiertos e interoperables, para facilitar su acceso. Se incluye en esta apertura de datos la publicación proactiva relevante y de interés sobre gestión presupuestaria, procesos de compras y adquisiciones, contratos, declaración de bienes e intereses de las autoridades, lo cual permite incrementar la transparencia y la rendición de cuentas.

- La apertura de procesos (open process) y el uso de redes sociales y plataformas para la participación ciudadana (también llamado gobierno 2.0). Persigue facilitar la comunicación e interacción y aprovechar el conocimiento y la experiencia de los ciudadanos para ayudar en el diseño y ejecución de políticas públicas. ${ }^{40}$

\footnotetext{
${ }^{38}$ Sandoval-Almazán, Rodrigo, "Gobierno abierto y transparencia: construyendo un marco conceptual", Convergencia, Revista de Ciencias Sociales, vol. 22, núm. 68, pp. 203-227.

${ }^{39}$ Ramírez-Alujas, Álvaro V., "Gobierno abierto y modernización de la gestión pública. Tendencias actuales y el (inevitable) camino que viene. Reflexiones seminales", en Revista Enfoques: Ciencia Política y Administración Pública (Chile), vol. IX, núm. 15, Universidad Central de Chile, Santiago de Chile, diciembre 2011, pp. 99-125.

Amoroso Fernández, Yarina y Brito Reyes, Irina, "Gobierno electrónico: clave del éxito", XV Congreso de Derecho Iberoamericano de Derecho e Informática, UNAM, México, 2010, pp. 36-37.

${ }^{40}$ Ramirez-Alujas, Álvaro, "Gobierno abierto y modernización de la gestión pública. Tendencias actuales y el (inevitable) camino que viene. Reflexiones seminales", Revista Enfoques: Ciencia Politica y Administración Pública, vol. 9, núm. 15, p. 108.
} 
La promulgación del memorando sobre Transparencia y Gobierno Abierto, de 21 de enero de $2009,{ }^{41}$ se basa en tres pilares básicos: ${ }^{42}$

- Transparencia (saber). Un gobierno transparente proporciona información sobre lo que está haciendo, sobre sus planes de acción y sus fuentes de datos.

- Participación (tomar parte). Un gobierno participativo promueve el derecho de la ciudadanía a participar activamente en la formulación de políticas públicas y facilitar el camino para que las administraciones públicas se beneficien del conocimiento, idea y experiencia de los ciudadanos.

- Colaboración (contribuir). Un gobierno colaborativo compromete a los ciudadanos y demás agentes sociales con el esfuerzo por trabajar conjuntamente para resolver los problemas nacionales. Esto permite la cooperación y el trabajo coordinado no sólo con la ciudadanía, sino con las empresas y asociaciones.

\section{Datos abiertos}

Los datos abiertos son aquellos que cualquier persona puede utilizar, reutilizar y distribuir libremente. Se encuentran sujetos, cuando más al requerimiento de atribución y de compartirse de la misma manera en que aparecen, así lo estableció la Asociación Internacional Open Knowledge Foundation desde su creación en el 2004.

La oCDE ha establecido que, para incluir en este concepto, los datos del gobierno tienen que estar disponibles para todo aquel que quiera tener acceso a ellos y reutilizarlos, así como proporcionarse con la mayor cantidad posible de detalles y de forma oportuna. Para hacerlo, por un lado, los datos tienen que estar disponibles y ser accesibles; por otro, debe autorizarse su utilización y redistribución. Según la $0 \mathrm{CDE},{ }^{43}$ los criterios que deben considerarse en este rubro incluyen:

\footnotetext{
${ }^{41}$ En la administración del presidente Obama de Estados Unidos, la promulgación del Memorando sobre Transparencia y Gobierno Abierto, del 21 de enero de 2009, donde se hace un uso intensivo de la tecnología como un instrumento catalizador de las acciones para promover apertura en los gobiernos de cara a los desafios del milenio. ${ }^{42}$ Ramirez-Alujas, Álvaro, "Gobierno abierto y modernización de la gestión pública. Tendencias actuales y el (inevitable) camino que viene. Reflexiones seminales", Revista Enfoques: Ciencia Política y Administración Pública, vol. 9, núm. 15, p. 109.

${ }^{43}$ Organización para la Cooperación y el Desarrollo Económico, Gobierno abierto en América Latina, París, ocde, 2015, p. 115.
} 
- Los datos se encuentran en formato legible por máquina, ya que la captura de textos o imágenes puede requerir mucho tiempo.

- Los datos se publican en formatos abiertos; se dan a conocer las especificaciones sin necesidad de un software específico para utilizarlo.

- Los datos están disponibles por medio de descargas a granel, lo cual permite el acceso a conjuntos de datos completos.

- Los datos se publican en forma oportuna.

- Los datos se enlazan: las consultas más sofisticadas de los usuarios requieren relaciones estructuradas entre las bases de datos gubernamentales, habilitadas por tecnologías de la web semántica que convierten grandes cantidades de datos a formatos de datos enlazados.

- Los usuarios tienen el derecho de reutilizar datos sin discriminación.

\section{Política sobre datos abiertos en México}

En febrero de 2015, se publicó el decreto por el que se establece la regulación en materia de datos abiertos. ${ }^{44} \mathrm{Su}$ objeto es regular la forma mediante la cual los datos de carácter público, generados por las dependencias y entidades de la administración pública federal y por las empresas productivas del Estado, se pondrán a disposición de la población como datos abiertos. El propósito de dicha medida es facilitar su acceso, uso, reutilización y redistribución para cualquier fin, conforme con los ordenamientos jurídicos aplicables.

En este decreto encontramos la definición de datos abiertos, entendidos como los datos digitales de carácter público accesibles en línea, que pueden ser usados, reutilizados y redistribuidos, por cualquier interesado. ${ }^{45}$ Así también, se establece que, para ser considerados como datos abiertos, los conjuntos de datos deberán contar con las características mínimas siguientes: ${ }^{46}$

- Gratuitos. Se obtendrán sin entregar a cambio contraprestación alguna.

- No discriminatorios. Serán accesibles sin restricciones de acceso para los usuarios.

- De libre uso. Citarán la fuente de origen como único requerimiento para usarlos libremente.

- Legibles por máquinas. Deberán estar estructurados, total o parcialmente,

\footnotetext{
44 "Decreto por el que se establece la regulación en materia de datos abiertos", Diario Oficial de la Federación, 20 de febrero, 2015.

${ }^{45} \mathrm{Cfr}$. artículo segundo fracción $\mathrm{V}$ del Decreto por el que se establece la regulación en materia de datos abiertos.

${ }^{46} \mathrm{Al}$ respecto, véase artículo quinto del Decreto por el que se establece la regulación en materia de datos abiertos.
} 
para ser procesados e interpretados por equipos electrónicos de manera automática.

- Integrales. Deberán contener, en la medida de lo posible, el tema que describen a detalle y con los metadatos necesarios.

- Primarios. Provendrán de la fuente de origen con el máximo nivel de desagregación posible.

- Oportunos. Serán actualizados periódicamente, conforme se generen.

- Permanentes. Se deberán conservar en el tiempo, para lo cual se mantendrán disponibles las versiones históricas relevantes para uso público.

La política de datos abiertos es un documento que orienta a las instituciones del Gobierno de la república en la publicación de datos en el portal datos.gob. mx. En junio de 2015, se publicó por primera vez la guía para las instituciones de la administración pública. ${ }^{47}$

En febrero de 2016, se publicó el acuerdo por el que se modifican las políticas y disposiciones para la estrategia digital nacional, en materia de tecnologías de la información y comunicaciones, y la de seguridad de la información. Asimismo, se modificó el Manual Administrativo de Aplicación General en dichas materias. ${ }^{48}$ En este último, dentro de las políticas para la estrategia digital nacional, se prevé cumplir con las disposiciones aplicables en materia de datos abiertos, protección de datos personales, seguridad de la información y derechos de autor. ${ }^{49}$

\section{Contrataciones públicas electrónicas en el sector petrolero}

Otro cambio en cuanto a la nueva estructura de Pemex se observa en el sistema de contrataciones públicas. La empresa deberá contar con un sistema de información pública sobre sus proveedores y contratistas que se actualice periódicamente. Debe contener la información de los últimos cinco años de los contratos celebrados, así como el historial de cumplimiento de los mismos, e incluir, en su caso, la ampliación, incremento o ajuste en dichos contratos. ${ }^{50}$

\footnotetext{
47 "Guía de la Implementación de la Política de Datos Abiertos", Diario Oficial de la Federación, 18 de junio, 2015.

${ }^{48}$ Publicado en el Diario Oficial de la Federación: 4 de febrero de 2016.

${ }^{49}$ Artículo 19, fracción VI del "Acuerdo que tiene por objeto emitir las políticas y disposiciones para la Estrategia Digital Nacional, en materia de tecnologías de la información y comunicaciones, y en la de seguridad de la información, así como establecer el Manual Administrativo de Aplicación General en dichas materias", Diario Oficial de la Federación, 8 de mayo, 2014.

${ }^{50} \mathrm{Cfr}$. Artículo 85 de la LPM.
} 
La información sobre contratación pública comunicada al exterior de Pemex se transmite por diferentes canales: ${ }^{51}$

- Se desarrolló un micrositio dentro del portal de internet para consulta de proveedores y público en general. El sitio contiene información, por ejemplo, sobre licitaciones abiertas públicas, procesos de invitación restringida y relaciones con proveedores.

- En cumplimiento de la ley en materia de transparencia, la información sobre contratación pública de Pemex se carga en el Portal de Obligaciones de Transparencia, donde todas las entidades públicas federales publican activamente la información requerida.

- Como se mencionó anteriormente, la Ley de Pemex ${ }^{52}$ y las disposiciones generales de contratación ${ }^{53}$ establecen que la empresa desarrollará el sistema de información pública de proveedores y contratistas (SIPPC), el cual se actualizará con regularidad y contendrá información sobre los contratos formalizados durante los últimos cinco años. Además, el SIPPC contiene información sobre la nacionalidad y las actividades de negocios de los proveedores, los resultados de la evaluación de su desempeño, su cumplimiento de los términos y calendarios del contrato, sanciones, cumplimiento de regulaciones ambientales y certificaciones de calidad.

- Las convocatorias para licitación en la modalidad de licitación pública internacional en el marco de los tratados de libre comercio se publican en el Diario Oficial de la Federación.

En las disposiciones generales de contratación para Pemex y sus empresas subsidiarias se contempla el procedimiento tanto de forma electrónica como presencial, conforme a lo siguiente: ${ }^{54}$

- Los procedimientos de contratación se podrán realizar a través de medios electrónicos o de manera presencial, o por una combinación de los anteriores, salvaguardando la confidencialidad de las propuestas en los términos que se señalen en la convocatoria.

\footnotetext{
${ }^{51}$ Organización para la Cooperación y el Desarrollo Económico, Estudio sobre las contrataciones públicas de Pemex. Adaptándose al cambio en la industria petrolera, París, OCDE, 2017, p. 45.

${ }^{52} \mathrm{Cfr}$. Artículo 85 de la LPM.

${ }^{53} \mathrm{Cfr}$. Artículo 22 de las "Disposiciones Generales de Contratación para Petróleos Mexicanos y sus Empresas Productivas Subsidiarias", Diario Oficial de la Federación, 27 de enero, 2016.

${ }^{54}$ Cfr. Artículo 17 de las Disposiciones General de Contratación.
} 
- En los procedimientos que se realicen por medios electrónicos, los sobres serán generados mediante el uso de tecnologías que aseguren la autenticidad y resguarden la confidencialidad de la información, de tal forma que sean inviolables, de acuerdo con las disposiciones técnicas que formen parte del sistema para conducir los procedimientos de contratación por medios electrónicos que al efecto establezca Procura y Abastecimiento..$^{55}$

- Los actos relacionados con los procedimientos de contratación se publicarán en el portal de internet del Área de Procura y Abastecimiento, o en cualquier otro medio de difusión que se establezca, para efectos de notificación a todos los interesados.

En el ámbito del sector público, el uso de la tecnología digital ha sido un impulsor estratégico para aumentar la eficiencia y apoyar la eficacia de políticas públicas al crear gobiernos más abiertos, transparentes, innovadores, participativos y confiables. De esta forma, la contratación electrónica incrementa la eficiencia al facilitar el acceso a las licitaciones, impulsar la competencia y reducir cargas administrativas; también mejora la transparencia al ampliar la rendición de cuentas a las autoridades públicas. ${ }^{56}$

El reto para Pemex consiste en sentar las bases de un sistema como este y lograr que funcione en la práctica, de modo que los proveedores y la empresa disfruten por igual de los beneficios. En 2015 puso en operación la herramienta de contratación electrónica SAP-Arriba. Desde el 1 de noviembre de 2016, todos los contratos deberían negociarse y realizarse en dicha plataforma electrónica. El sistema brinda un entorno empresarial integrado (contratación pública, recursos humanos, finanzas y otros). Sin embargo, aún se trabaja en algunas definiciones de procesos transversales para lograr la integración necesaria. ${ }^{57}$

A pesar de que el proceso de implementación ha sido lento, en abril de 2017 se publicaron las políticas y lineamientos para la utilización del nuevo sistema de contrataciones electrónicas Pemex (Siscep). ${ }^{58}$ Su objetivo consiste en regular la forma y los términos para la utilización del Siscep en los procedimientos

\footnotetext{
${ }_{55}$ Pemex Procura y Abastecimiento es una empresa productiva subsidiaria de Pemex creada en mayo de 2014, la cual se encarga de compras, adquisiciones y contratos con proveedores.

${ }^{56}$ Organización para la Cooperación y el Desarrollo Económico, Estudio sobre las contrataciones públicas de Pemex. Adaptándose al cambio en la industria petrolera, París, OCDE, 2017, p. 256.

${ }^{57}$ Organización para la Cooperación y el Desarrollo Económico, Estudio sobre las contrataciones públicas de Pemex. Adaptándose al cambio en la industria petrolera, París, OCDE, 2017, p. 260.

58 "Políticas y Lineamientos para la utilización del Sistema de Contrataciones Electrónicas Pemex (Siscep)", Diario Oficial de la Federación, 25 de abril, 2017.
} 
de contratación electrónicos o mixtos y eventos electrónicos, conforme con lo que dispone la ley especial y demás normativa aplicable. Tanto los servidores públicos de Pemex y sus empresas productivas subsidiarias, como los usuarios externos deben aplicar las políticas y lineamientos de forma obligatoria.

En el anexo único podemos encontrar un apartado de definiciones, entre las cuales destacan: 59

Comunicación de Incorporación. Acción a través de la cual el usuario interno envía al usuario externo la liga de acceso para participar en los procedimientos de contratación electrónicos o mixtos y en eventos electrónicos de bienes, arrendamientos, servicios y obras.

Evento electrónico. Cualquier acto realizado por un usuario interno que se presente durante los subprocesos de procura y abastecimiento de Petróleos Mexicanos y de sus empresas productivas subsidiarias que están incorporados en Siscep (planeación, programación, presupuestación y estrategias de contratación; concertación y contratación y administración de contratos) bajo el régimen especial en materia de adquisiciones, arrendamientos, obras y servicios, como son: análisis de mercado, encuestas de evaluación de desempeño, selección de proveedores o contratistas, eventos de abastecimiento estratégico (desarrollo de estrategias, acuerdos referenciales, contratos preparatorios $\mathrm{u}$ otro instrumento jurídico) o los eventos específicos de los procedimientos de contratación, entre otros.

Nube. Servicio de funcionalidad operativa y almacenamiento de información que se proporciona a través de internet. Permite a los usuarios utilizar aplicaciones para un proceso determinado y almacenar información de cualquier tipo alojada en servidores dedicados, es decir, en equipos que permanecen funcionando las 24 horas del día, los 365 días del año.

Participante. Es el usuario externo que interviene como persona física o moral en un procedimiento de contratación electrónico o mixto y evento electrónico.

Procedimiento de contratación electrónico. Es aquel que se lleva acabo únicamente a través de la utilización del Siscep.

126 Procedimiento de contratación mixto. Aquel que se lleva a cabo a través del Siscep, pero que permite realizar actos de forma presencial determinados por Pemex.

Sobre electrónico. El espacio de comunicación electrónica entre Pemex y los participantes en un procedimiento de contratación electrónico o mixto utilizado

\footnotetext{
59 "Políticas y Lineamientos para la utilización del Sistema de Contrataciones Electrónicas Pemex (Siscep)", Diario Oficial de la Federación, 25 de abril, 2017.
} 
para la entrega de las proposiciones por parte de los participantes dentro de un RFP. Para apoyar en la comprensión del registro de proveedores y contratistas y habilitación de usuarios externos en el Siscep, se estableció un proceso simplificado:

\begin{tabular}{|c|c|c|c|c|}
\hline $\begin{array}{l}\text { Usuario } \\
\text { Externo }\end{array}$ & $\begin{array}{c}\text { Ingresa a } \\
\text { www.pemex. } \\
\text { com }\end{array}$ & Registro & $\begin{array}{l}\text { Validación de } \\
\text { registro }\end{array}$ & $\begin{array}{c}\text { Generación } \\
\text { de usuario y } \\
\text { contraseña en } \\
\text { el SISCEP }\end{array}$ \\
\hline $\begin{array}{l}\text { Persona física o } \\
\text { persona moral } \\
\text { que desea } \\
\text { establecer una } \\
\text { relación con } \\
\text { Pemex. }\end{array}$ & $\begin{array}{c}\text { En la sección de } \\
\text { proveedores, el } \\
\text { usuario externo } \\
\text { deberá realizar } \\
\text { su registro. }\end{array}$ & $\begin{array}{l}\text { El registro se rea- } \\
\text { liza completando } \\
\text { un cuestionario } \\
\text { en el que se soli- } \\
\text { cita información } \\
\text { y documentación } \\
\text { de la persona } \\
\text { física o moral. } \\
\text { Para la gestión } \\
\text { segura de la } \\
\text { información } \\
\text { se genera una } \\
\text { cuenta de usuario } \\
\text { y contraseña de } \\
\text { registro que serán } \\
\text { distintas a las que } \\
\text { se generarán más } \\
\text { adelante para el } \\
\text { Siscep. }\end{array}$ & $\begin{array}{c}\text { Se verifica } \\
\text { y valida la } \\
\text { información y } \\
\text { documentación } \\
\text { proporcionada; } \\
\text { en caso de exis- } \\
\text { tir inconsisten- } \\
\text { cias se solicita } \\
\text { su corrección. } \\
\text { Para la gestión } \\
\text { y validación de } \\
\text { información } \\
\text { la Dopa puede } \\
\text { hacer recurso } \\
\text { a un servicio } \\
\text { proporcionado } \\
\text { por un tercero } \\
\text { especialista. }\end{array}$ & $\begin{array}{l}\text { La información } \\
\text { de registro se } \\
\text { transfiere a } \\
\text { la plataforma } \\
\text { electrónica del } \\
\text { Siscep. } \\
\text { Para la genera- } \\
\text { ción de usuario } \\
\text { y contraseña } \\
\text { es necesario } \\
\text { el manifiesto } \\
\text { de interés de } \\
\text { participación. }\end{array}$ \\
\hline
\end{tabular}

Fuente: "Políticas y Lineamientos para la utilización del Sistema de Contrataciones Electrónicas Pemex (Siscep)", Diario Oficial de la Federación, 25 de abril, 2017.

Además para promover la participación electrónica de las empresas que deseen participar como proveedores de Pemex, se oferta en la página oficial de internet un tutorial en cuanto al procedimiento para la habilitación en el sistema.

Sin duda, son comunes algunos de los desafíos a los que se enfrentan los países de la oCDE en cuanto al uso de tecnologías de información y comunicación. Uno de ellos tiene que ver con el escaso nivel de conocimientos y competencias para utilizar sistemas de contratación electrónica (48\%). El bajo nivel de cultura organizacional innovadora (41\%) y los escasos conocimientos de las oportunidades económicas planteadas por los sistemas de contratación 
electrónica (32\%) se identificaron como retos adicionales para las entidades contratantes.

Los problemas también se identificaron como retos para el personal de Pemex. En relación con posibles licitantes y proveedores, doce países miembro de la OCDE (41\%) identificaron dificultades para comprender o aplicar los procedimientos y retos en el uso de las funciones. ${ }^{60}$ Estos datos nos permiten afirmar que todavía se requiere multiplicar esfuerzos en el ámbito nacional e internacional para dotar de seguridad y certeza jurídica a las empresas que participen en los procesos de contrataciones públicas electrónicas.

A partir de la implementación del sistema nacional anticorrupción en México, y contrario a lo que establece la ley especial vigente, las contrataciones que realicen Pemex y sus empresas productivas subsidiarias ${ }^{61}$ se rigen por lo que dispone la Ley General de Responsabilidades Administrativas. ${ }^{62}$ En esta última se consideran, además de las responsabilidades administrativas de los servidores públicos, las faltas de particulares, es decir, los actos de personas físicas o morales privadas que estén vinculados con faltas administrativas.

Lo anterior es así porque cuando se expidió la Ley General de Responsabilidades Administrativas, se estableció un año para efectos de que la Ley Federal Anticorrupción en Contrataciones Públicas se abrogara. ${ }^{63}$

En el Sistema Nacional Anticorrupción, una persona física o moral, o un servidor público, pueden acudir ante la Unidad de Responsabilidades de Pemex para denunciar actos $\mathrm{u}$ omisiones que podrían constituir o vincularse con faltas administrativas. Con ello se inicia el procedimiento de investigación correspondiente, el cual puede concluir con una resolución en la que se sancionen faltas administrativas graves de servidores públicos y faltas de particulares.

En el caso de contrataciones públicas, incurrirá en colusión el particular que ejecute, con uno o más sujetos particulares, acciones que impliquen obtener un beneficio indebido en las contrataciones públicas de carácter federal, local o municipal.

También se considerará colusión cuando los particulares acuerden o cele128 bren contratos, convenios, arreglos o combinaciones entre competidores, cuyo objeto o efecto sea obtener un beneficio indebido u ocasionar un daño a la

\footnotetext{
${ }^{60}$ Organización para la Cooperación y el Desarrollo Económico, Estudio sobre las contrataciones públicas de Pemex. Adaptándose al cambio en la industria petrolera, París, OCDE, 2017, pp. 259-261.

${ }^{61}$ El artículo 86 de la LPM establece: "Las contrataciones que realicen Petróleos Mexicanos y sus empresas productivas subsidiarias estarán sujetas a lo dispuesto en la Ley Federal Anticorrupción en Contrataciones Públicas, entre otros ordenamientos. Al efecto, la Secretaría de la Función Pública será autoridad competente".

62 "Ley General de Responsabilidades Administrativas", Diario Oficial de la Federación, 18 de julio, 2016.

63 "Ley Federal Anticorrupción en Contrataciones Públicas", Diario Oficial de la Federación, 11 de junio, 2012.
} 
hacienda pública o al patrimonio de los entes públicos. Con relación a transacciones comerciales internacionales, la Secretaría de la Función Pública será la autoridad competente para realizar las investigaciones que correspondan.

Por lo anterior, en la medida en que el procedimiento de las contrataciones públicas se realice de forma completa en el sistema electrónico diseñado por Pemex, con pleno conocimiento de las partes que intervienen en su utilización, será más eficiente el uso y ejercicio de los recursos públicos. Esto siempre y cuando se cuente con los mecanismos de autenticidad y confidencialidad de la información que se sube al sistema, para otorgar certeza jurídica a las personas físicas o empresas que participan como proveedores.

\section{Conclusiones}

En México, el nuevo orden jurídico en materia energética pretende promover la libre competencia y concurrencia en los mercados de comercialización y expendio al público de los productos derivados del petróleo y otros hidrocarburos.

La constitución de Pemex como empresa productiva del Estado trajo consigo una serie de cambios sobre las actividades que realiza, para que sea eficiente, transparente y responsable. Entre dichas actividades se encuentran las contrataciones públicas en materia de adquisiciones, arrendamientos y servicios.

El gobierno abierto, a través de la apertura de datos y procesos, coadyuva al gobierno corporativo de las empresas públicas, como es el caso de Pemex. En este sentido, como se ha explicado, el proceso de contrataciones públicas se puede realizar de forma física, electrónica o ambas. Sin embargo, como estrategia de gobernanza para combatir la corrupción y favorecer la rendición de cuentas, la tendencia es que en el futuro todo el proceso de contratación pública se realice en la plataforma electrónica diseñada por Pemex.

Para la implementación de esta política de contrataciones públicas electrónicas, es necesario que todos los participantes en el proceso de contrataciones públicas tengan las habilidades y competencias en cuanto al uso de las tecnologías de información y comunicación. Esto se refiere tanto al personal que trabaja en Pemex y sus empresas subsidiarias, como a las personas físicas o jurídicas colectivas que deseen participar como posibles licitantes o proveedores. Para ello, Pemex debe coadyuvar a crear una cultura en cuanto al uso de las herramientas tecnológicas, mediante tutoriales, guías y manuales. En ella se mostrarían los beneficios de realizar los procedimientos en forma electrónica.

Además, Pemex debe establecer en su plataforma electrónica mecanismos que brinden confianza y certeza jurídica a las personas o empresas que desean 
participar en sus procesos licitatorios o de contrataciones públicas, en cuanto a la autenticidad y confidencialidad de la información que se sube al sistema.

\section{Bibliografía}

AlcÁNTARA, Armando, "Gobernanza, gobierno y gobernabilidad en la educación superior”, en Bertha Lerner, Ricardo Uvalle y Roberto Moreno (coords.), Gobernabilidad y gobernanza en los albores del siglo xxi y reflexiones sobre el México contemporáneo, México, Universidad Nacional Autónoma de México, Instituto de Investigaciones Sociales, Instituto de Administración Pública del Estado de México, 2012.

Amparo en revisión 415/2015 resuelto el 25 de enero de 2017 por la Segunda Sala de la Suprema Corte de Justicia de la Nación, promovido por Petróleos Mexicanos y Pemex-Refinación.

“Constitución Política de los Estados Unidos Mexicanos”, Diario Oficial de la Federación, 5 de febrero, 1917; última reforma, 24 de febrero, 2017.

"Decreto por el que se reforman y adicionan los artículos 25, 27 y 28 de la Constitución Política de los Estados Unidos Mexicanos en Materia de Energía”, Diario Oficial de la Federación, 20 de diciembre, 2013.

"Decreto por el que se establece la regulación en materia de datos abiertos", Diario Oficial de la Federación, 20 de febrero, 2015.

"Disposiciones Generales de Contratación para Petróleos Mexicanos y sus Empresas Productivas Subsidiarias", Diario Oficial de la Federación, 27 de enero, 2016.

Florio, Massimo, "Empresas públicas contemporáneas en una perspectiva global: teoría y evidencia”, Revista del clad Reforma y Democracia, núm. 60.

Guajardo Soto, Guillermo, "La empresa pública y sus definiciones en el largo plazo" en Guillermo Guajardo y Alejandro Labrador (coords.), La empresa pública en México y en América Latina: entre el mercado y el Estado, México, Universidad Nacional Autónoma de México - Centro de Investigaciones Interdisciplinarias en Ciencias y Humanidades - Instituto Nacional de Administración Pública, 2015.

"Guía de la Implementación de la Política de Datos Abiertos", Diario Oficial de la Federación, 18 de junio, 2015.

"Ley de Hidrocarburos", Diario Oficial de la Federación, 11 de agosto, 2014; última reforma, 15 de noviembre, 2016.

"Ley de Petróleos Mexicanos", Diario Oficial de la Federación, 28 de noviembre, 2008; abrogada, 11 de agosto, 2014.

“Ley de Petróleos Mexicanos”, Diario Oficial de la Federación, 11 de agosto, 2014.

"Ley Federal Anticorrupción en Contrataciones Públicas", Diario Oficial de la Federación, 11 de junio, 2012. 
“Ley General de Responsabilidades Administrativas”, Diario Oficial de la Federación, 18 de julio, 2016.

“Ley Orgánica de la Administración Pública Federal”, Diario Oficial de la Federación, 29 de diciembre, 1976; última reforma, 19 de mayo, 2017.

MeIJER, AlBert, “Open government: connecting vision and voice”, International Review of Administrative Sciences, núm. 78.

Organización para la Cooperación y el Desarrollo Económico, Estudio sobre las contrataciones públicas de Pemex. Adaptándose al cambio en la industria petrolera, París, OCDE, 2017.

Organización para la Cooperación y el Desarrollo Económico, Guía de la ocde de diligencia debida para la participación significativa de las partes interesadas del sector extractivo, París, OCDE, 2016.

Organización para la Cooperación y el Desarrollo Económico, Gobierno abierto en América Latina, París, oCDE, 2015.

Organización para la Cooperación y el Desarrollo Económico, línea directrices de la oCDE para empresas multinacionales, París, OCDE, 2011.

Organización para la Cooperación y el Desarrollo Económico, Directrices sobre el Gobierno Corporativo de las Empresas Públicas, París, oCDE, 2011.

Organización para la Cooperación y el Desarrollo Económico, Principios de gobierno corporativo de la OCDE, París, OCDE, 2004.

Pérez Fuentes, Gisela María y Cantoral Domínguez, Karla, Teoría y práctica de los derechos reales en estudios de caso, México, Novum, 2014.

"Políticas y Lineamientos para la utilización del Sistema de Contrataciones Electrónicas Pemex (Siscep)”, Diario Oficial de la Federación, 25 de abril, 2017.

RAmirez-AluJAS, ÁlVARo, "Gobierno abierto y modernización de la gestión pública. Tendencias actuales y el (inevitable) camino que viene. Reflexiones seminales", Revista Enfoques: Ciencia Política y Administración Pública, vol. 9, núm. 15.

SÁnchez, José JuAn, "Usos de los conceptos de gobernabilidad y gobernanza (una manera de diferenciarlos)" en Bertha Lerner, Ricardo Uvalle y Roberto Moreno (coords.), Gobernabilidad y gobernanza en los albores del siglo XXI y reflexiones sobre el México contemporáneo, México, Universidad Nacional Autónoma de México - Instituto de Investigaciones Sociales - Instituto de Administración Pública del Estado de México, 2012.

SAndoval-AlmazÁn, Rodrigo, "Gobierno abierto y transparencia: construyendo un marco conceptual”, Convergencia, Revista de Ciencias Sociales, vol. 22, núm. 68.

“The World's Biggest Public Companies”, Forbes. [Consulta: 2 de junio, 2017]. Disponible en: https://www.forbes.com/global2000/list/\#

“Tesis 2a. XLV/2017”, Décima Época, Gaceta del Semanario Judicial de la Federación, libro 40, Tomo II, marzo, 2017, p. 1392.

“Tesis 2a. XLVI/2017”, Décima Época, Gaceta del Semanario Judicial de la Federación, libro 40, tomo 2, marzo, 2017, p. 1392. 